\title{
The impact of technological innovation on building a sustainable city
}

\author{
Chai-Lee Goi
}

Correspondence:

goi.chai.lee@curtin.edu.my

Department of Marketing, Faculty of

Business, Curtin University, 98009

Miri, Sarawak, Malaysia

\begin{abstract}
By 2050, the population living in major cities, especially in developing countries, will have increased twofold. With the increasing majority of the population occurring in urban areas, it is crucial to focus on how technological innovation can help to deliver a sustainable future. A sustainable city strives to create a sustainable living environment through the use of technology. Thus, the main objective of this paper is to review the impact of technological innovation on building a more sustainable city. Technological innovation has changed the overall effectiveness and benevolence over time and with regard to sustainability. A sustainable city involves development that meets the needs of the present without compromising the ability of future generations to meet their own needs. Sustainable development encompasses all aspects of environmental stewardship, social development, and economic progress.
\end{abstract}

Keywords: Technological innovation, Sustainable city, Environment, Social, Economy

\section{Review}

This review paper will be significantly important to the society in terms of building a more sustainable city especially related to economy, social and environment through the technological innovation. Organising a sustainability agenda requires at the start an interactive approach that involves public authorities, citizens and business stakeholders. This is important to obtain broader support and increase momentum. Furthermore, the study will be important to the policy makers, particularly to Ministry of Science, Technology \& Innovation and City Council in developing a more sustainable plans and strategies in the future.

\section{Introduction}

Cities can be classified based on the cities proper (administrative), the extent of the urban area, or the metropolitan regions [1]. The Organisation for Economic Co-operation and Development (OECD) [2] also classified the size of cities based on four categories. First, a large metropolitan area has a population of 1.5 million or more. Second, the metropolitan area has a population between 500,000 and 1.5 million people. Third, a medium-sized urban area has a population of about 200,000 to 500,000 people. Fourth, a small-sized urban area has a population of about 500,000 to 200,000 people.

(c) The Author(s). 2017 Open Access This article is distributed under the terms of the Creative Commons Attribution 4.0 International License (http://creativecommons.org/licenses/by/4.0/), which permits unrestricted use, distribution, and reproduction in any medium, provided you give appropriate credit to the original author(s) and the source, provide a link to the Creative Commons license, and indicate if changes were made. 
"The world is undergoing the largest wave of urban growth in history. More than half of the world's population now lives in towns and cities" [3]. From 1950 to 2010, 1.3 billion people live in small cities, 632 million people live in medium-sized cities, and 570 million people live in large cities [4]. By 2050, the population living in cities, especially in developing countries, will have increased twofold. Thus, "the problems created by rampant urbanisation are among the most important challenges of our time. They also represent one of the greatest opportunities - and responsibilities - for the private sector. Business is uniquely positioned to shape the sustainable, economically competitive cities of the future" [5]. With urban areas containing the increasing majority of the population, it is very important to focus on how technological innovation can help deliver a sustainable future. A smart sustainable city strives to create a sustainable living environment through the use of technology [6]. "Transforming cities for the better through sustainable technology" [7].

There are several issues that pose a major impact on the quality of life that drives the shift towards a more sustainable city. First, there is a rapid rise in the number of people who move into and live in cities. Trends and lifestyle have led to the development of infrastructure and buildings, along with cultural and social practices without destroying nature and the environment. Therefore, there is a need to create a smart city by involving smart energy management, infrastructure development, waste and environment management, public-private partnerships, economic development plans, smart healthcare, and smart education programs. Second, it is a huge challenge to transform a city through sustainable technological innovation. Sometimes a city fails to recognise the challenges of the digital divide [8]. The development of the tomorrow sustainable city must be well planned, offers services, involves the community, and includes well-linked whole systems.

Thus, the key question that has been addressed is whether technological innovation has an impact on building a sustainable city.

This paper provides an original approach that offers a discussion of the impact of technological change on building a sustainable city. Furthermore, a substantial number of references are included to indicate the specific researches for the analysis of this topic. The paper is organised as follows:

- The first section is related to technological innovation. This section covers the overview of technological innovation and also innovation in technological change.

- The second section is related to the discussion of a sustainable city. This section covers a few issues related mainly to the environment, social, and economy.

- The third section covers the impact of technological innovation on building a sustainable city.

- The final section discusses the conclusion and the limitations for future research.

\section{Technological innovation}

\section{Overview}

Technological innovation involves "the introduction of something new, or a new idea, method, or device" [9]. Sustainable development must take into account the effectiveness of the technology [10]. Technological innovation, as part of technological change [8], allows organisations to test new ideas at speeds and prices that were never 
anticipated a decade ago [11]. "Changes in consumption patterns can drive the creation of new technologies necessary for sustainability and their adoption and diffusion at the desired pace. Success in bringing about these changes will require substantial reorganisation of the economy and society and changes in lifestyles. Economic and financial incentives for the creation and adoption of new technologies will be needed, which may include innovative policy reforms" [4].

\section{Innovation in technological change}

Innovation is related to how consumers perceive an idea, a practice, a product, or an object as a new thing, and begins with consumers' awareness of the innovation. Meanwhile, diffusion is a process in which information about the innovation is conveyed through certain channels over time among the consumers [12]. Vergragt [13] discussed that innovation goes beyond invention. It refers to the spread of new technology into the wider society.

The development of technological innovation has led to the sixth generation. Rothwell [14] mentioned that the development of technological innovation in the first stage up to the fifth has already begun since the 1950s. The generations of innovation include technology push, market/demand pull, coupling, cross-functioning, as well as integration and networking. Hasan and Adomdza [15] added another generation, a sixth generation, known as design-driven innovation. It means to design new products whilst simultaneously creating a need for consumers. Technological change and sustainability are closely related to each other. Both factors form the innovation in order to improve the effectiveness of environmental stewardship, social development, and economic progress [16].

Technology is transforming innovation at its core, and the speed of change involves evolution, effect, and what is ahead [11]. Gartner [17] revealed three distinct technology trends that are poised to be of the highest priority in terms of facing rapidly accelerating digital innovation. The combination of digital innovation in the business model will establish and empower a city to be more sustained. The summary of technology innovation can be illustrated into Fig. 1.

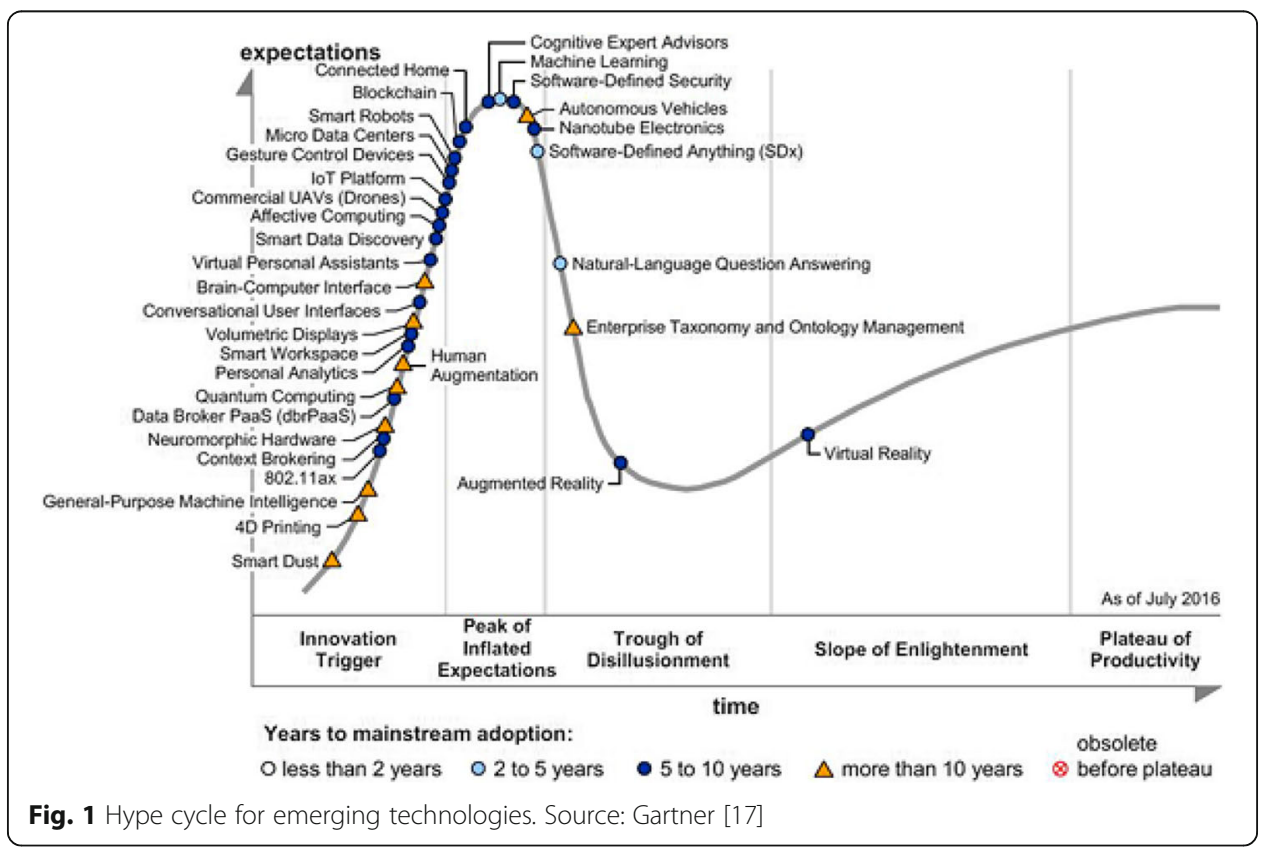


- Transparently immersive experiences. Technology becomes more human-centric, where it will introduce transparency between people, businesses, and things. Also, the evolution of technology becomes more adaptive, contextual, and fluid within the workplace, at home, and interacting with businesses and other people.

- The perceptual smart machine age. Smart technology will be the most disruptive over the next decade. This will allow organisations with smart machine technologies to harness data in order to adapt to new situations and solve problems.

- The platform revolution. Emerging technology is revolutionising the concepts of how platforms can be defined and used. This includes shifting technical infrastructure to ecosystem-enabling platforms, which is laying the foundations for entirely new business models that are forming the bridge between humans and technology.

Although a research related to technology innovation has reached 100 years, the convergence of research related to science, technology, and innovation only began in 1960 [18]. The overall technological innovation system has garnered widespread attention, especially beyond the context of sustainability. Besides technological innovation system, there have been other aspects that are related to system delineation, spatial aspects, transitions, politics, and policy recommendations [19].

There are two main components related to the study of innovation. First is the use of patent scale, whereby the data is used to study the geography of innovation and also the spatial extent of knowledge spillover. Second is the measuring of innovation by using survey. This refers to a set of questions that asks establishments whether a new product, process, or organisational innovation has been introduced. The questions are also related to whether the innovation is new [20]. Reviews have been conducted on updated academic articles that were published in 2017 in order to further understand the trends of technological innovation.

One of the main problems of urban sustainability is related to energy consumption. Velmurugan [21], in his study, focused on the sustainable perspectives of energy consumption. The results showed that the energy saved in 1 year could be used power 60,000 European homes. In practice, manufacturers, especially, can improve energy efficiency through design and implement energy-efficient projects on their own or enter into energy performance contracting (EPC), which mainly includes shared and guaranteed savings [22]. Also, Miao's [23] study discussed the overall energy system and $\mathrm{CO}_{2}$ emission. The population scale is the most important factor in residential energy consumption and $\mathrm{CO}_{2}$ emissions.

The world has witnessed extreme environmental deterioration over the past few decades. Rapid development in urban areas has caused severe environmental pollution and ecological destruction. Green innovation is an important approach to achieve sustainable city development. There is even a relationship between legitimacy pressure, profitability, and green innovation. Green innovation will lay the foundation for balancing profit and environmental responsibility, and at the same time achieve the harmonious development of socioeconomic environmentally [24]. The continuity of technological innovation involves green technological innovation, green institutional innovation, and green business model innovation [25]. 
Technological innovation is not just related to road management system, building management system, and public facilities management, but also to solid waste management. The problems of solid waste management include the amount and composition of waste generated, rapid expansion of urban areas, funding issues, rapid technological advancement, and limited energy and raw materials [26, 27].

To ensure the success of technological innovation, it requires a consolidation policy. Isaksson et al. [28] proposed layering and parallel policy-making. It is a complementary concept to understand the challenges associated with the implementation of sustainable mobility. A number of studies have also been identified to be related to policies such as environmental policies [29], transport policies [30], and policy and planning for shrinking cities [31].

\section{Sustainable city}

\section{Overview}

A sustainable city means "development that meets the needs of the present without compromising the ability of future generations to meet their own needs" [32]. In the twenty-first century, there has been a shift from sustainability assessment to smart-city goals, transformed into smart sustainable city [33].

The framework of a city should be holistically integrated with the urban sustainable principle [34]. Basically, most of the literatures that have been studied so far correlated innovation and city development together. Innovation is considered as a driver of economic growth. Innovation is also an open process, with innovative organisations drawing ideas, contacts, and learning opportunities from their environment [35].

Four dimensions of sustainable development have been identified in building a more sustainable city $[36,37]$ :

- Environmental dimension is related to the objectives of the conservation and preservation of the environment. This includes aspects such as atmosphere, soil, water, oceans and seas, biodiversity, and sanitation.

- Social dimension is related to the objective that involves the satisfaction of human needs. They include population, employment and income, health, education, housing, and security, which aim to reflect the level of education, income distribution, and living conditions.

- Economic dimension is concerned with the efficiency of production processes and changes in consumption patterns.

- Institutional dimension includes the ability and effort spent by governments and societies to implement changes required for an effective implementation of sustainable development.

\section{Environmental dimension}

"Cities are at the crossroads of implementing system changes for sustainable development. Paradigm shifts are needed in multiple dimensions to redefine the relations of cities with the environment" [38]. "Cities impact their immediate environment, as well as the global environment" [39]. According to Sharma [40], a sustainable city includes environmental sustainability, heritage conservation, appropriate technology, infrastructure efficiency, 
placemaking, social access, transit-oriented development, regional integration, human scale, and institutional integrity.

Energy consumption in urban areas is as much as $75 \%$. It also accounts for $70 \%$ of carbon dioxide emissions. To meet the needs of the population in urban areas, infrastructure development sometimes ignores ecological sustainability. Living in urban areas has contributed to pressure on the ecosystem. Human ecological footprint has exceeded the capacity of terrestrial ecosystems for as much as $50 \%$. The level of ecosystem services at the moment is risky at a critical level of degradation. Thus, there are five major challenges for urban sustainability. These include ecological footprint, ecosystem services and biodiversity, investment for sustainability, the good life, as well as leadership and cooperation [41].

So far, a number of current issues related to the environment have been published. There is a close relationship between sustainable urban development and environmental sustainability. Therefore, it is important to formulate any strategy of transformation, renewal, and regeneration. A few studies have even evaluated the environmental outcomes and effectiveness of regeneration programmes, especially in relation to green spaces, access to public transportation, climate change, and seismic-risk reduction [42].

Due to the high population density in the city, transport system is a key issue being discussed. Nanaki et al. [43] mentioned that an efficient and flexible transport system is essential for a future of low carbon transport system. Their study also found that the differences in the levels of emissions coming from the different systems of each city depict differences in the quality and utilisation of transportation networks. Carbon emissions are correlated with income. Per capita incomes are higher in a city, which results in higher average per capita demand in major emissions sources. High carbon emissions have also increased from households. By understanding that behaviours affect energy consumption will be useful in promoting low carbon household [44].

El Ghorab and Shalaby [45] discussed a green city as a new approach for planning and developing a sustainable city. Sustainable urban development appears to be closely connected with the discursive production of green city or eco-city. The implementation of sustainable urban development focuses on green infrastructure, transit-oriented development, brownfield redevelopment, and carbon reduction plan [46]. The purpose of a green city is to strive to reduce environmental impact by reducing waste, expanding recycling, lowering emissions, and increasing housing density, while expanding open space and encouraging the development of sustainable local businesses [47]. Thus, a number of studies have been conducted that are related to green value. A study conducted by Vyas and Jha [48] and Shad et al. [49] stated that green building construction is considered to be an essential practice to achieve sustainability. Serrao-Neumann et al. [50] discussed the importance of connecting land use and water planning. Ogie et al.s [51] study emphasised on flood mitigation infrastructure, whereby it is crucial to remove accumulating floodwater from low-lying areas where drainage is naturally poor due to a very low slope gradient. A study by Zhang et al. [52] concluded that the operating efficiency, operating performance, and service quality of a drainage enterprise is determined by its sustainable development level that involves urban wastewater treatment, construction of drainage engineering, operation and maintenance, and consulting. Peng et al. [53] evaluated ecosystems and the impacts caused by the change in the environment. A study conducted by Thorne et al. [54] included wider aspects. It involves making the allocation of land for urban development more sustainable and bears an impact on food production, ecosystem services, and biodiversity conservation. 
The Economist Intelligence Unit (EIU) [55] developed a green city index in alignment with green management. It covers $\mathrm{CO}_{2}$ emissions, energy, buildings, land use, transport, water and sanitation, waste management, air quality, and environmental governance (refer to Table 1). Another model of green management proposed 12 green guidelines for creating a happier, healthier, and a more sustainable and green city. The 12 green guidelines fall into three key categories: urban form (urban growth boundary, transit-oriented development, mixed-use, small blocks, and public green space), transportation (non-motorised transit, public transit, and car control), and energy and resources (green buildings, renewable and distributed energy, waste management, and water efficiency). They are also consistently moving towards to a smart city, which involves smart telecommunication, smart mobility, smart energy management, smart governance, smart public services, and smart safety [56].

\section{Social dimension}

The aspect of social development towards building a more sustainable city "occurs when the formal and informal [processes, systems, structures, and relationships] actively support the capacity of current and future generations to create healthy and liveable communities". This social aspect covers equity, diversity, quality of life, democracy and governance, and inter-connectedness [57].

Bertacchini and Segre [58] addressed two major issues about social quality in cultureled urban regeneration plans. First is a plan in terms of the instrumental involvement of the community in participation practices. Second is an urban policy that is related to the creative city notion that needs to be implemented.

Living sociability involves the city itself and a combination of culture and nature [59]. The study conducted by Guzmán et al. [60] measured the link between cultural heritage management and sustainable urban development and identified three levels of a monitoring system of the management system: strategic level, operational level, and monitoring level.

The World Economic Forum [61] identified three indicators for social sustainability (refer to Fig. 2). The first indicator aims to assess a population's access to basic necessities. It is a measure of inclusion, as well as a measure of the fulfilment of basic

Table 1 ElU's The Green City Index

\begin{tabular}{|c|c|c|c|}
\hline $\mathrm{CO} 2$ & Energy & Buildings & Transport \\
\hline $\begin{array}{l}\text { - CO2 intensity } \\
\text { - CO2 emissions } \\
\text { - cO2 reduction } \\
\text { strategy }\end{array}$ & $\begin{array}{l}\text { - Energy consumption } \\
\text { - Energy intensity } \\
\text { - Renewable energy } \\
\text { consumption } \\
\text { - Clean and efficient } \\
\text { energy policies }\end{array}$ & $\begin{array}{l}\text { - Energy consumption of } \\
\text { residential buildings } \\
\text { - Energy-efficient buildings } \\
\text { standards } \\
\text { - Energy-efficient buildings } \\
\text { initiatives }\end{array}$ & $\begin{array}{l}\text { - Use of non-car } \\
\text { transport } \\
\text { - Size of non-car } \\
\text { transport network } \\
\text { - Green transport } \\
\text { promotion } \\
\text { - Congestion reduction } \\
\text { policies }\end{array}$ \\
\hline Waste and land use & Water & Air quality & $\begin{array}{l}\text { Environmental } \\
\text { governance }\end{array}$ \\
\hline $\begin{array}{l}\text { - Municipal waste } \\
\text { production } \\
\text { - Waste recycling } \\
\text { - Waste reduction } \\
\text { policies } \\
\text { - Green land use } \\
\text { policies }\end{array}$ & $\begin{array}{l}\text { - Water consumption } \\
\text { - System leakages } \\
\text { - Wastewater system } \\
\text { treatment } \\
\text { - Water efficiency and } \\
\text { treatment policies }\end{array}$ & $\begin{array}{l}\text { - Nitrogen dioxide } \\
\text { - Sulphur dioxide } \\
\text { - Ozone } \\
\text { - Particulate matter } \\
\text { - Clean air policies }\end{array}$ & $\begin{array}{l}\text { - Green action plan } \\
\text { - Green management } \\
\text { - Public participation in } \\
\text { green policy }\end{array}$ \\
\hline
\end{tabular}

Source: The Economist Intelligence Unit (EIU) [55] 


\begin{tabular}{|l|l|l|l|}
\hline Access to basic necessities & Vulnerability to shocks & Social cohesion \\
\hline Access to sanitation & Vulnerable employment & Income Gini index \\
\hline Access to improved drinking water & Extent of informal economy & Social mobility \\
\hline Access to healthcare & Social safety net protection & Youth unemployment \\
\hline
\end{tabular}

Fig. 2 Three indicators for social sustainability. Source: The World Economic Forum [61]

physical needs. The second indicator is linked to the concept of perceived economic security. It aims to evaluate a population's vulnerability to economic exclusion. Finally, the third indicator assesses social cohesion.

\section{Economic dimension}

There is a relationship between balance economic goals with social and environmental. As mentioned by Soubbotina [62], this balance can be discussed with reasons:

- If environmental and social losses resulting from economic growth turn out to be higher than economic benefits, the overall result for people's wellbeing becomes negative.

- The economic growth itself inevitably depends on its natural and social conditions. To be sustainable, it must rely on a certain amount of natural resources and services provided by nature such as pollution absorption and resource regeneration. The economic growth must be constantly nourished by the fruits of human development.

Bullock et al. [63] studied the economic contribution to the sustainability and efficient functioning of a city, especially the benefits in an economic context of private individual benefits and public goods benefits. First, the economic assessment focuses on the impact on businesses. Second, in terms of private benefits, transport investment provides a mixture of private and public goods benefits. The timesaving in private benefits is a key motivation. Third, for business sales, perceptions of change in sales have been found to vary by location and nature or characteristics of products. Fourth, in terms of health benefits, it includes time-saving and reduced costs of congestion, pollution, and $\mathrm{CO}_{2}$ emissions. The cycling activities provide physical exercise, which contributes to health and reduces expenditure on healthcare. Finally, in terms of time-saving and wider economic benefits, it contributes to the city's economy by improving connectivity between journey, origin, and destination, and by reducing journey time.

\section{The impact of technological innovation on building a sustainable city}

It is very important to understand the challenges of a contemporary city. The challenge is due to the increasingly complex nature and the variety of the contemporary city [64]. Thus, a future city needs to balance economic development with energy efficiency and the preservation of natural resources in order to improve the quality of life [65]. "Balancing the immediate 
needs of today without compromising the needs of tomorrow is at the heart of being a sustainable city, and of this report" [66].

A study done by Van Osch and Avital [67] demonstrated the nature of sustainable innovation, which is sustained by the materiality, social structures, and institutional frameworks that comprise the overall sociotechnical system in which innovation takes place. The social value can be leveraged for shaping alternative courses of action, creating technological innovation, and developing novel practices that create sustainable value for society.

Sustainability challenges have affected the formation of planning and the vision to create a future city or smart city.

- Han et al. [68] proposed the conceptual vision of a sustainable urban future in 2050. To achieve a low carbon society, various technological advances in transportation, buildings, and industries are among those that can contribute towards this end.

- Kourtit et al. [69] proposed a roadmap for innovative strategic urban policy. This includes developing urban agglomeration as engines of creativity and technological innovation; exploiting technological opportunities and developing a sustainable urban system; laying the foundation for social cohesion and social capital; and developing ecological footprint and improve climate neutrality of urban areas.

- Future urban configurations should concentrate on the efficient use of resources and opportunities in contributing to economic growth; deploying infrastructure, physical assets, and amenities; providing social services; minimising poverty, inequalities, and segments of the population; and protecting the environment and preserving natural assets [70].

Arcadis [66] released a list of the 100 most sustainable cities in the world. Most cities are from Europe and Asia. Ten of the most sustainable cities are Zurich, Singapore, Stockholm, Vienna, London, Frankfurt, Seoul, Hamburg, Prague, and Munich. Though there are three significant areas of correlation (people or social, planet or environment, and profit or economic), there are also other elements that make a city more sustainable:

- The urban regeneration and innovation hubs for the future development, as the city transforms itself from a manufacturing centre to a knowledge, technology, and innovation centre for the nation.

- The urban planning policies to strengthen the city's identity, global competitiveness, development direction, and innovation in the living environment.

- Adopting technological innovation, especially new innovative technologies, cyclical processes, and business models.

\section{Conclusions}

The world is undergoing an endless wave of urban growth. By 2050, the population living in cities will have increased twofold. One of the reasons that lead to this process is because a smart sustainable city strives to create a sustainable living environment through the use of technology. Technological innovation has affected effectiveness and delivered a sustainable future for city development. Thus, this paper plays a crucial role in analysing the impact of technological innovation on building a sustainable city. 
The first analysis found that technological innovation has changed the overall effectiveness and benevolence with regard to sustainability. With the rapid growth of a city, technological innovation has changed the patterns of people. The use of technology has led to significant development of the sixth-generation technology. There is even a relationship between legitimacy pressure, profitability, and green innovation. Green innovation is an important approach for achieving sustainable city development. Second, a sustainable city creates an enduring way of life across environment, social, and economy. There are various aspects to redefine the relationship between city and environment. It is important to formulate strategies, transformations, renewals, and regenerations. This involves creating a green city in terms of urban form, transportation system, and energy and resources. Social aspects involve equity, diversity, quality of life, democracy and governance, and inter-connectedness. Meanwhile, the economy contributes to the sustainability and efficient functioning of a city, especially the benefits in an economic context of private individual benefits and public goods benefits. Overall, the impact of technological innovation has a positive impact on building a more sustainable city, especially in terms of environment, social, and economy. Thus, authorities, especially local government and city planners, should not neglect the importance of technological innovation.

However, this research has a few limitations. First, the preparation of this paper is based on the number of publications. Thus, it is without the field collection of primary data. Second, the lifespan of each sustainable city framework or model is not analysed. Technological change is speeding up. The pace of innovation is not just accelerating slightly, but exponentially [71]. The problem is whether the people can rival with the speed of technological innovation. Technological innovation advancements are accelerating faster than the abilities of the people to try to adapt and use them [72]. Also, the implementation of the framework or model for a sustainable city is usually more focused on a specific city, rather than to all cities. By adopting a sustainable model from other cities without the guided mould of a city is likely leading to a disaster. However, it is important to think global, act local.

Future research will be conducted for the continuation of this study. More specifically, it is the causal relationships that must be researched in order to measure the relationship between the influence of technological innovation on building a sustainable city (refer to Fig. 3). There are undiscovered potentials in technological innovation,

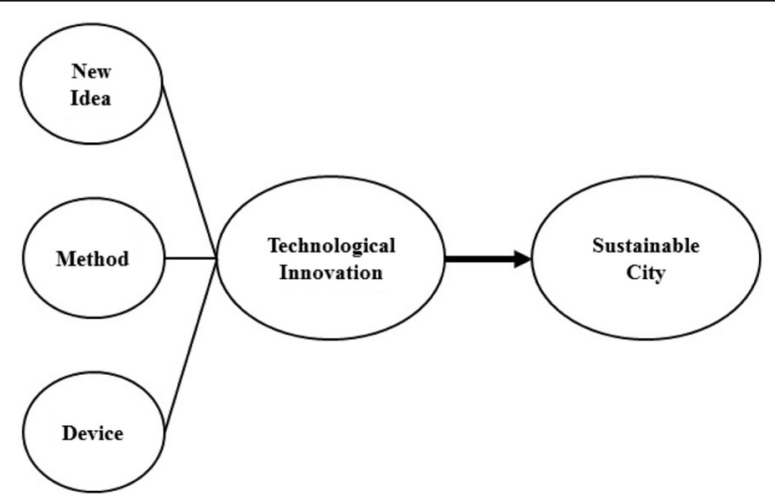

Fig. 3 Research model 
especially new ideas, methods, and devices to transform a city towards sustainability. Thus, the design of the proposed research propositions is as follows:

- Proposition 1: The new idea of technological innovation has an impact on building a sustainable city.

- Proposition 2: The method of technological innovation has an impact on building a sustainable city.

- Proposition 3: The device of technological innovation has an impact on building a sustainable city.

The research will be based on quantitative research, and a city will be chosen. Thus, we will choose Kuala Lumpur as our research city. As discussed by [73], Kuala Lumpur has a great policy and smart-city framework. Malaysia, as a whole, is a multi-racial, multi-religion, and multi-cultural country. One of the challenges of a city is the need to ensure economic, social, and environment sustainability now and in the medium- and long-term future. In the recent decade, researchers have discussed the importance of social sustainability within urban studies [74]. The data collection shall involve government sectors, especially city council, residents of the city, and business sectors.

Author's contributions

CLG prepared and drafted the article. The author has read and approved the final manuscript.

Competing interests

The author declares that he has no competing interests.

\section{Publisher's Note}

Springer Nature remains neutral with regard to jurisdictional claims in published maps and institutional affiliations.

Received: 16 June 2016 Accepted: 12 September 2017

Published online: 11 October 2017

References

1. The United Nations Children's Fund (n.d). https://www.unicef.org. Accessed 7 Jan 2017

2. The Organisation for Economic Co-operation and Development (OECD) (2017) Urban population by city size (indicator). https://data.oecd.org/popregion/urban-population-by-city-size.htm. Accessed 12 May 2017

3. United Nations Population Fund (n.d) Urbanization. http://www.unfpa.org/urbanization. Accessed 22 Feb 2017

4. United Nations (2013) World economic and social survey 2013-sustainable development challenges. https:// sustainabledevelopment.un.org/content/documents/2843WESS2013.pdf. Accessed 15 Dec 2015

5. Macomber JD (2013) Building sustainable cities. Harv Bus Rev 91(7/8):40-50

6. International Telecommunication Union (2014) ITU-T focus group on smart sustainable cities: an overview of smart sustainable cities and the role of information and communication technologies. http://www.itu.int/en/ITU-T/ focusgroups/ssc/Documents/Approved_Deliverables/TR-Overview-SSC.docx. Accessed 15 Dec 2015

7. Siemens (2013) Transforming cities for the better through sustainable technology. https://w3.siemens.com/topics/ global/en/sustainable-cities/Documents/Transforming_Cities_en.pdf. Accessed 15 Dec 2015

8. The Conversation (2016) Three big challenges for smart cities and how to solve them. http://theconversation. com/three-big-challenges-for-smart-cities-and-how-to-solve-them-59191. Accessed 16 Mar 2016

9. Merriam-Wester (n.d) Innovation. https://www.merriam-webster.com/dictionary/innovation. Accessed 20 June 2017

10. Making the Modern World (n.d) Sustainable cities: the role of technology. http://www.makingthemodernworld. org.uk/learning_modules/geography/04.TU.01/?section=8. Accessed 21 June 2017

11. Brynjolfson E, Schrage M (2009) The new, faster face of innovation. The Wall Street Journal http://www.wsj.com/ articles/SB10001424052970204830304574130820184260340. Accessed 16 Dec 2015

12. Yu CS, Tao YH (2009) Understanding business-level innovation technology adoption. Technovation 29(2):92-109

13. Vergragt PJ (2006) How technology could contribute to a sustainable world. GTI Paper Series. Frontiers of a Great Transition, Tellus Institute

14. Rothwell R (1992) Successful industrial innovation: critical factors for the 1990s. R\&D Manag 22(3):221-240

15. Hasan D, Adomdza G (2013) The sixth generation. http://dalalhasan.weebly.com/the-sixth-generation.html. Accessed 16 Dec 2015

16. Villa N, Mitchell S (2010) Connecting cities - Achieving sustainability through innovation. Cisco Internet Business Solutions Group (IBSG) http://www.cisco.com/c/dam/en_us/about/ac79/docs/innov/Connecting_Cities Sustainability_Through_Innovation_IBSG_1021FINAL.pdf. Accessed 10 June 2016 
17. Gartner (2016), Gartner's 2016 hype cycle for emerging technologies identifies three key trends that organizations must track to gain competitive advantage. http://www.gartner.com/newsroom/id/3412017. Accessed 12 May 2017

18. Godin B (2010) "Innovation studies": the invention of a specialty (Part I). Working paper No. 7, Project on the Intellectual History of Innovation. Institut national de la recherche scientifique (INRS), Montreal

19. Markard J, Hekkert M, Jacobsson S (2015) The technological innovation systems framework: Response to six criticisms. Environmental Innovation and Societal Transitions 16:76-86

20. Shearmur R (2012) Are cities the font of innovation? A critical review of the literature on cities and innovation. Cities 29(Supplement 2):S9-S18

21. Velmurugan MS (2017) Sustainable perspectives on energy consumption, EMRF, environment, health and accident risks associated with the use of mobile phones. Renew Sust Energ Rev 67:192-206

22. Ouyang J, Shen H (2017) The choice of energy saving modes for an energy-intensive manufacturer considering non-energy benefits. J Clean Prod 141:83-98

23. Miao L (2017) Examining the impact factors of urban residential energy consumption and CO2 emissions in China - Evidence from city-level data. Ecol Indic 73:29-37

24. Li D, Zheng M, Cao C, Chen X, Ren S, Huang M (2017) The impact of legitimacy pressure and corporate profitability on green innovation: evidence from China top 100. J Clean Prod 141:41-49

25. Fei J, Wang Y, Yang Y, Chen S, Zhi Q (2016) Towards eco-city: The role of green innovation. Energy Procedia 104:165-170

26. Tchobanoglous G, Theisen H, Vigil S (1993) Integrated solid waste management. McGraw-Hill Inc, Singapore

27. Moh YC, Abd Manaf L (2017) Solid waste management transformation and future challenges of source separation and recycling practice in Malaysia. Resour Conserv Recycl 116:1-14

28. Isaksson K, Antonson H, Eriksson L (2017) Layering and parallel policy making — complementary concepts for understanding implementation challenges related to sustainable mobility. Transp Policy 53:50-57

29. Zheng D, Shi M (2017) Multiple environmental policies and pollution haven hypothesis: evidence from China's polluting industries. J Clean Prod 141:295-304

30. Boussauw K, Vanoutrive T (2017) Transport policy in Belgium: translating sustainability discourses into unsustainable outcomes. Transp Policy 53:11-19

31. He SY, Lee J, Zhou T, Wu D (2017) Shrinking cities and resource-based economy: the economic restructuring in China's mining cities. Cities 60(Part A):75-83

32. Rees WE, Roseland M (1991) Sustainable communities: planning for the 21st century. Plan Canada 31(3):15-26

33. Ahvenniemi H, Huovila A, Pinto-Seppä I, Airaksinen M (2017) What are the differences between sustainable and smart cities? Cities 60(Part A):234-245

34. About-de Chastenet C, Belziti D, Bessis B, Faucheux F, Le Sceller T, Monaco F, Pech P (2016) The French econeighbourhood evaluation model: contributions to sustainable city making and to the evolution of urban practices. J Environ Manag 176:69-78

35. Shearmur R (2017) Are cities the font of innovation? A critical review of the literature on cities and innovation. Cities 29(Supplement 2):S9-S18

36. Instituto Brasileiro de Geografia e Estatística (2015) Indicators of sustainable development. http://www.ibge.gov.br. Accessed 8 Mar 2017

37. Barbosa MTG, Almeida M (2017) Developing the methodology for determining the relative weight of dimensions employed in sustainable building assessment tools for Brazil. Ecol Indic 73:46-51

38. Kılkış \$̧ (2016) Sustainable development of energy, water and environment systems index for Southeast European. J Clean Prod 130:222-234

39. O'Brien G (2016) Cities: Saviours of the planet? In: Wilkinson SP, Xia J, Chen B (eds) Sustainable buildings and structures. Taylor \& Francis, London, pp 21-27

40. Sharma PD (2008) Sustainable and green city development-for achieving all-round better environment. https:// saferenvironment.wordpress.com/2008/09/29/sustainable-and-green-city-development-for-achieving-all-roundbetter-environment. Accessed 15 Dec 2015

41. WWF Sweden (2013) Five challenges for sustainable cities. http://www.wwf.se/source.php/1523656/ Sustainablecities_ENG.pdf. Accessed 15 Dec 2015

42. La Rosa D, Privitera R, Barbarossa L, La Greca P (2017) Assessing spatial benefits of urban regeneration programs in a highly vulnerable urban context: a case study in Catania, Italy. Landsc Urban Plan 157:180-192

43. Nanaki EA, Koroneos CJ, Roset J, Susca T, Christensen TH, De Gregorio HS, Rybka A, Kopitovic J, Heidrich O, Amparo López-Jiménez P (2017) Environmental assessment of 9 European public bus transportation systems. Sustainable Cities and Society 28:42-52

44. Ye H, Ren Q, Hu X, Lin T, Xu L, Li X, Zhang G, Shi L, Pan B (2017) Low-carbon behavior approaches for reducing direct carbon emissions: household energy use in a coastal city. J Clean Prod 141:128-136

45. El Ghorab HK, Shalaby HA (2016) Eco and Green cities as new approaches for planning and developing cities in Egypt. Alexandria Engineering Journal 55:495-503

46. Freytag T, Gössling S, Mössner S (2014) Living the green city: Freiburg's Solarsiedlung between narratives and practices of sustainable urban development. Local Environment - The International Journal of Justice and Sustainability 19(6):644-659

47. The Environmental Magazine (2009) What are 'green cities'? https://phys.org/news/2009-03-green-cities.html. Accessed 15 June 2016

48. Vyas GS, Jha KN (2017) Benchmarking green building attributes to achieve cost effectiveness using a data envelopment analysis. Sustainable Cities and Society 28:127-134

49. Shad R, Khorrami M, Ghaemi M (2017) Developing an Iranian green building assessment tool using decision making methods and geographical information system: case study in Mashhad city. Renew Sust Energ Rev 67:324-340

50. Serrao-Neumann S, Renouf M, Kenway SJ, Low CD (2017) Connecting land-use and water planning: Prospects for an urban water metabolism approach. Cities 60(Part A):13-27

51. Ogie Rl, Dunn S, Holderness T, Turpin E (2017) Assessing the vulnerability of pumping stations to trash blockage in coastal mega-cities of developing nations. Sustainable Cities and Society 28:53-66 
52. Zhang Y, Zhao T, Zhang Z, Wan J, Feng X, Liang X, Zhou A (2017) Modeling and dynamic assessment on sustainable development of drainage enterprise: application of a coupled system dynamics - comprehensive assessment model. J Clean Prod 141:157-167

53. Peng J, Liu Y, Li T, Wu J (2017) Regional ecosystem health response to rural land use change: a case study in Lijiang City, China. Ecol Indic 72:399-410

54. Thorne JH, Santos MJ, Bjorkman J, Soong O, Ikegami M, Seo C, Lee H (2017) Does infill outperform climateadaptive growth policies in meeting sustainable urbanization goals? A scenario-based study in California, USA Landsc Urban Plan 157:483-492

55. The Economist Intelligence Unit (EIU) (2012) The Green City Index - a summary of the Green City Index research series. https://www.siemens.com/entry/cc/features/greencityindex_international/all/en/pdf/gci_report_summary.pdf. Accessed 3 Mar 2016

56. Huang CC, Busch C, He D, Harvey H (2015) 12 green guidelines - CDBC's green and smart urban development guidelines. http://energyinnovation.org/wp-content/uploads/2015/12/12-Green-Guidelines.pdf. Accessed 2 Feb 2017

57. Hodgson N (n.d) Social sustainability assessment framework. Institute for Sustainability and Technology Policy, Murdoch University. http://integral-sustainability.net/wp-content/uploads/sas4-2-hodgson.pdf. Accessed 20 June 2017

58. Bertacchini E, Segre G (2016) Introduction: Culture, sustainable development and social quality: A paradigm shift in the economic analysis of cultural production and heritage conservation. City. Culture and Society 7:69-70

59. Cananzi DM (2016) City, nature, culture. New way of living sociability (the case of Reggio Calabria). Procedia Social and Behavioral Sciences 223:745-749

60. Guzmán PC, Pereira Roders AR, Colenbrander BJF (2017) Measuring links between cultural heritage management and sustainable urban development: an overview of global monitoring tools. Cities 60(Part A):192-201

61. World Economic Forum (2012) The Global Competitiveness Report 2012-2013. http://www3.weforum.org/docs/ WEF_GlobalCompetitivenessReport_2012-13.pdf. Accessed 15 Dec 2015

62. Soubbotina TP (2004) Beyond economic growth — an introduction to sustainable development, 2nd edn. The World Bank https://openknowledge.worldbank.org/bitstream/handle/10986/14865/ 2489402nd0edition0Beyond0economic0growth.pdf?sequence=1\&isAllowed=y. Accessed 16 Dec 2015

63. Bullock C, Brereton F, Bailey S (2017) The economic contribution of public bike-share to the sustainability and efficient functioning of cities. Sustainable Cities and Society 28:76-87

64. Güell JMF, López JG (2016) Cities futures. A critical assessment of how future studies are applied to cities. Foresight 18(5):454-468

65. Mezher T (2011) Building future sustainable cities: the need for a new mindset. Constr Innov 11(2):136-141

66. Arcadis (2016) Sustainable cities index 2016. https://www.arcadis.com/media/0/6/6/\%7B06687980-3179-47AD89FD-F6AFA76EBB73\%7DSustainable\%20Cities\%20Index\%202016\%20Global\%20Web.pdf. Accessed 12 Mar 2017

67. Van Osch W, Avital M (2010) The road to sustainable value: the path-dependent construction of sustainable innovation as sociomaterial practices in the car industry. In: Thatchenkery T, Cooperrider DL, Avital M (eds) Positive design and appreciative construction: from sustainable development to sustainable value, vol 3. Emerald Group Publishing Limited, UK, pp 99-116

68. Han J, Fontanos P, Fukushi K, Herath S, Heeren N, Naso V, Cecchi C, Edwards P, Takeuchi K (2012) Innovation for sustainability: toward a sustainable urban future in industrialized cities. Sustain Sci 7(Supplement 1):91-100

69. Kourtit K, Nijkamp P, Partridge MD (2015) Challenges of the new urban world. Applied Spatial Analysis and Policy 8(3):199-215

70. Riffat S, Powell R, Aydin D (2016) Future cities and environmental sustainability. Future Cities and Environment 2:1-23

71. Miller B (2013) Is technological change speeding up? How can you tell? The Innovation Files. https://www. innovationfiles.org/is-technological-change-speeding-up-how-can-you-tell/. Accessed 2 Feb 2017

72. Hooper C (2015) Is technology evolving faster than our ability to adapt? https://www.linkedin.com/pulse/ technology-evolving-faster-than-our-ability-adapt-chris-hooper. Accessed 12 June 2016

73. Yau KLA, Lau SL, Chua HN, Kwan SCC (2016) Greater Kuala Lumpur as a smart city: a case study on technology opportunities. 8th International Conference on Knowledge and Smart Technology, Chiangmai

74. Monfaredzadeh T, Krueger R (2015) Investigating social factors of sustainability in a smart city. Procedia Engineering 118:1112-1118

\section{Submit your manuscript to a SpringerOpen ${ }^{\circ}$ journal and benefit from:}

- Convenient online submission

- Rigorous peer review

Open access: articles freely available online

High visibility within the field

- Retaining the copyright to your article 